\title{
SOCIAL COMPETENCE IN SCHIZOPHRENIA: PREMORBID ADJUSTMENT, SOCIAL SKILL, AND DOMAINS OF FUNCTIONING
}

\author{
Kim T. Mueser,* Alan S. Bellack, Randall L. Morrison and John T. Wixted \\ Medical College of Pennsylvania at EPPI, Philadelphia, U.S.A.
}

(Received 30 January 1989; revised 21 June 1989; re-revised 29 August 1989)

\begin{abstract}
Summary-The relations between premorbid adjustment, social skill, and domains of functioning (symptoms, social adjustment) were examined in a group of 107 schizophrenic, schizoaffective, and affective disorder patients. Premorbid sexual adjustment was moderately correlated with social skill in the schizophrenic and schizoaffective patients. Schizophrenic patients had the lowest premorbid adjustment and social skill, followed by schizoaffectives, and then affective patients. Within the schizophrenic group, social skill was significantly related to both current social adjustment and negative symptoms, but not positive symptoms. Similar but weaker effects were found for premorbid adjustment. The results suggest that deficits in social skill are correlated with poor premorbid and morbid social adjustment of schizophrenics.
\end{abstract}

\section{INTRODUCTION}

PREMORBID social functioning has repeatedly been found to be poorer in schizophrenic than other psychiatric patients and such functioning is an important predictor of the course and outcome of the illness (Phillips, 1953; KaY \& LindenmaYer, 1987). A patient's premorbid adjustment is determined by the nature and quality of his or her social and sexual relations prior to the onset of illness, such as whether the patient was socially involved with friends from adolescence through early adulthood, or whether he or she dated, had sexual relationships, or married. Individuals who have attained these common milestones before their illness are considered to be more socially competent or to have greater "developmental maturity", since they possess the skills necessary to achieve socially approved life experiences (ZIGLER \& PHILIPS, 1961). Thus, an individual's social competence refers to his or her overall ability or capacity to solve life problems and achieve instrumental and affiliative goals (Zubin \& Spring, 1977; Liberman, Mueser, Wallace, Jacobs, EcKman, \& MASSEL, 1986b).

The theoretical importance of social competence as a mediator of outcome has grown as evidence has accumulated that the inter-episodic social functioning of schizophrenics is also related to the likelihood of symptom exacerbations and rehospitalizations, as well as future social adjustment (Serban, 1975; Strauss \& Carpenter, 1977; DeJong, Giel, SLOOF, \& WIERSMA, 1985). Recent psychosocial interventions aimed at improving social competence have focused on remediating patients' coping or social skills (BELLACK, TURNER, Hersen \& Luber, 1984; Hogarty, Anderson, Reiss, Komblith, Greenwald, Javna, \&

*Address for correspondence: K. T. Mueser, Medical College of Pennsylvania at EPPI, 3200 Henry Avenue, Philadelphia, PA 19129, U.S.A. 
MAdonia, 1986; Liberman, Mueser, \& Wallace, 1986a), an important component of competence. Social skills refer to a specific set of abilities, including cognition, verbal, and nonverbal behaviors that are needed for effective interpersonal performance. Social competence is the overall ability of the patient to impact favorably on his or her social environment. Social adjustment is the actual meeting of instrumental and affiliative needs that is the natural consequence of social competence (LrBERMAN et al., 1986b).

Both patients with schizophrenia and affective disorders have been found to have pronounced deficits in social skills (e.g., Argyle, 1981; Boswell \& Murray, 1981). These deficiencies may reflect the primary influence of the illness itself (e.g., negative symptoms), the iatrogenic effects of institutionalization and social impoverishment, and the lack of appropriate role models or learning opportunities during childhood and adolescence, as reflected by poor premorbid adjustment. However, despite the fact that premorbid adjustment is predictive of outcome in schizophrenia, and early research on social skills training has shown promising results, the relations between these two constructs have not yet been explored.

The present study was conducted in order to examine the relations between premorbid adjustment and current social skill in a group of schizophrenic, schizoaffective, and affective disorder patients. Since social competence has long been hypothesized to influence the chronicity of mental illness, the relationship of premorbid adjustment and social skill to age of illness onset, duration of illness, and current age were also explored within each diagnostic group. Finally, the relationship between premorbid adjustment, social skill, and the following domains of the illness was explored within the sample of schizophrenic patients: symptoms, social adjustment, and work adjustment.

\section{METHOD}

\section{Subjects}

Subjects were 57 schizophrenics (26 paranoid, 31 non-paranoid), 16 schizoaffectives, and 33 affective disorder patients ( 29 bipolar, 4 unipolar-depressed) between the ages of 18 and 55 years old who were admitted to Eastern Pennsylvania Psychiatric Institute (EPPI). The demographic characteristics of the patient sample are presented in Table 1.

Patients in all three diagnostic groups met DSM-III-R criteria (AMERICAN PsYchIATRIC Association, 1987), based on diagnostic interviews with either the Structured Clinical Interview for DSM-III (SCID; SPITZER \& Williams, 1985) or the Schedule for Affective Disorders and Schizophrenia (SADS; ENDICOTT \& SPITZER, 1978). Affective patients were included only if they had a duration of illness of at least 6 months, so as to be comparable to the schizophrenic sample on chronicity. To assure reliability of diagnoses, $25 \%$ of the interviews were rated by an independent evaluator, with a concordance rate of $100 \%$.

Assessments were conducted 1-3 weeks after admission, when the patient's treatment team had determined that his or her major symptoms had been sufficiently controlled by psychotropic medications to permit participation in the social skill role play assessments and interviews.

\section{Assessment of social skill}

Social skill was evaluated using a role play test (i.e., a simulated social encounter). An individual who performs well on this test is assumed to have the necessary skills in his 
Table 1. Characteristics of Schizophrenic, Schizoaffective, and Affective Disorder Patients

\begin{tabular}{lccc}
\hline & $\begin{array}{c}\text { Schizophrenia } \\
(n=57)\end{array}$ & $\begin{array}{c}\text { Schizoaffective } \\
(n=16)\end{array}$ & $\begin{array}{c}\text { Affective } \\
\text { disorder } \\
(n=33)\end{array}$ \\
\hline Age (SD) & $32.1(10.1)$ & $33.2(9.6)$ & $34.8(10.1)$ \\
SES* (SD) & $4.7(0.6)$ & $4.8(0.7)$ & $4.1(0.7)$ \\
Sex & 33 & 11 & 18 \\
$\quad$ Male & 24 & 5 & 15 \\
Female & & & 27 \\
Race & 33 & 6 & - \\
$\quad$ White & 23 & - & 18 \\
$\quad$ Black & 1 & 11 & 11 \\
$\quad$ Oriental & 43 & 3 & 4 \\
Marital status & 10 & 2 & $24.3(8.5)$ \\
$\quad$ Single & 4 & $22.3(4.4)$ & $5.5(5.5)$ \\
$\quad$ Divorced & $21.6(6.7)$ & $5.2(2.0)$ & $9.4(21.7)$ \\
$\quad$ Age of onset (SD) & $6.7(5.0)$ & $7.3(6.7)$ & $10.5(8.3)$ \\
Prior hospitalizations (SD) & $10.1(9.1)$ & $10.9(7.0)$ & \\
Prior months in hospital (SD) & $10.5(10.5)$ & & \\
Duration of illness in years (SD) & & & \\
\hline
\end{tabular}

*Socioeconomic status (SES) based on Hollingshead and Redlich scale (1958).

or her behavioral repertoire, although other factors may interfere in real-life situations. Conversely, persons who have the requisite skills may perform poorly on the test due to factors related to the test situation (e.g., anxiety). Despite these limitations, role play tests have been successful in discriminating among different groups of psychiatric patients and are sensitive to the effects of social skills training (BELLACK, 1983).

Following a description of the role play test, the patient participated in two practice scenarios and 12 test scenarios. Each scenario required a short interaction with a confederate (research assistant), and the patient was told to respond as if the encounter was actually taking place in the natural environment. Before each role play encounter began, the patient read a description of the scenario from an index card, and it was briefly explained aloud. Scenarios either began with a verbal prompt by the confederate or were initiated by the patient, and included three verbal exchanges between the patient and confederate. Four of the scenarios involved initiating social interactions with peers (e.g., at a day treatment center), four scenarios assessed positive assertion (e.g., the peer said or did something nice for the patient), and four scenarios dealt with negative assertive situations (e.g., another patient changes the TV while the patient is watching).

All role plays were videotaped and subsequently rated on three different dimensions of social skill: nonverbal skills (gaze, length, meshing, affect), verbal content (praise/ appreciation for positive assertion scenarios, request/compliance for negative assertion scenarios), and overall social skill. Three sets of raters were used to rate the role plays. One set rated the nonverbal skills, one set rated verbal content, and one set rated overall social skill. Raters were trained to a minimum inter-rater reliability of at least $r=.80$ on each dimension. To assure reliability of ratings over time and to guard against rater drift, 
periodic reliability assessments were conducted, and one-third of the role plays were rated by a second rater. Reliabilities were high for all categories, ranging from intraclass correlation coefficients (ICCs) of .72 (Overall Social Skill) to .90 (Affect).

\section{Premorbid adjustment}

Premorbid social adjustment was measured using the abbreviated version of the Phillips Scale developed by HARRIS (1975). This scale yields scores on two factors: premorbid social functioning and premorbid sexual functioning. The abbreviated Phillips Scale has adequate reliability and validity, and circumvents many of the problems of the earlier version (Strauss, KLORMAN, KoKES, \& SACKSTEDER, 1977). The information was obtained via chart review by three raters, all blind to patients' social skill, and social adjustment. Reliabilities were high between the raters, ranging from ICCS of .87 to .98 .

\section{Social adjustment and quality of life}

Social and vocational adjustment were assessed with interviews using the Social Adjustment Scale-II (SAS; Schooler, Hogarty, \& WeIssman, 1979). The SAS provides measures of adjustment across the following areas of functioning: social and leisure activities, work, household responsibility, activity external to the family unit, and general adjustment.

A different facet of adjustment was measured with a semi-structured interview, the Quality of Life Scale (QLS; Heinrichs, Hanlon, \& CarPenter, 1984). The QLS was designed to measure deficit symptoms of schizophrenia, and yields scores on four different factors: interpersonal relations, instrumental role functioning, intrapsychic foundations (e.g., motivation), and common objects and activities (e.g., owning a watch, reading a newspaper).

\section{Symptomatology}

Symptoms were rated in a semi-structured interview using the Brief Psychiatric Rating Scale (BPRS; Overall \& Gorham, 1962) and the Scale for the Assessment of Negative Symptoms (SANS; ANDREASEN, 1982). The BPRS yields scores on five factors: anxietydepression, anergia, activation, hostility, and thought disorder. The SANS also consists of five factors: blunting, alogia, apathy, asociality, and attention. Inter-rater reliabilities were high for all the interview-based measures (SAS, QLS, BPRS, SANS) except one, with ICCs ranging from .64 (SAS household adjustment) to .93 (BPRS depression-anxiety). The exception was the activation subscale on the BPRS, for which the ICC was lower $(\mathrm{ICC}=.44)$, but nevertheless statistically significant $(P<.001)$.

\section{RESULTS}

\section{Premorbid adjustment and social skills measures}

Three independently rated measures of social skill were formed for each patient: overall social skill, nonverbal skill, and verbal content. An Overall Social Skill (OSS) score was derived by calculating the mean OSS rating for the 12 role play scenarios. The Nonverbal Skill (NS) score was derived by first calculating a mean for each of the four nonverbal 
Table 2. Correlations between Premorbid Adjustment (Premorbid Social, Premorbid Sexual, Premorbid Total) and Social Skill (Overall Social Skill, Nonverbal Skill, Verbal Skill) for Schizophrenic (S). Schizoaffective (SA). and Affective Disorder (A) Patients

\begin{tabular}{|c|c|c|c|c|c|c|c|c|c|}
\hline & \multicolumn{3}{|c|}{ Overall social skill } & \multicolumn{3}{|c|}{ Nonverbal skill } & \multicolumn{3}{|c|}{ Verbal skill } \\
\hline & $\mathrm{S}$ & SA & A & $\mathrm{S}$ & SA & A & $\mathrm{S}$ & SA & A \\
\hline Premorbid social & .16 & .41 & .24 & .08 & .07 & .01 & .05 & .28 & .16 \\
\hline Premorbid sexual & $.23^{*}$ & $.59+\ddagger$ & $-.06+$ & $.30 \dagger \S$ & -.15 & $-.25 \S$ & .10 & $.48^{*}$ & .23 \\
\hline Premorbid total & $.23^{*}$ & $.59+11$ & $.10 \mid$ & $.22 * 11$ & -.01 & $-.17 \|$ & .06 & $.45^{*}$ & .25 \\
\hline
\end{tabular}

Note: ${ }^{*}=P<.05 ; \dagger=P<.01$.

$\ddagger$ Significantly different correlations. Fisher's $r$ to $Z$ transformation $(Z=2.22, P<.02$ (one-tailed).

$\S$ Significantly different correlations. Fisher's $r$ to $Z$ transformation $(Z=2.49, P<.007$ (one-tailed)).

I| Significantly different correlations within the OSS and NS categories, Fisher's $r$ to $Z$ transformation $(Z=1.74$, $P<.05$ (one-tailed)).

skills (gaze, length, meshing, affect) across the 12 scenarios. Then, each skill was standardized (i.e., $z$-scores were computed) and the scores were summed across the skills to form a single sum for each patient. The Verbal Content (VC) score was computed similarly to NS for the two verbal content skills rated: praise/appreciation and request/compliance.

To explore the relationship between the premorbid measures of social competence (social adjustment, sexual adjustment, overall adjustment) and social skill (OSS, NS, VC), Pearson correlations were computed between these two sets of variables separately for the three diagnostic groups. Differences in the strength of the correlations between the diagnostic groups were tested using Fisher's $r$ to $Z$ transformation. One-tailed significance tests were used because previous research has found premorbid adjustment is more predictive of outcome in schizophrenics than affective patients (Rosen, KLEIN, LEVENSTEIN, \& ShaHINIAN, 1969; Westermeyer \& HARROW, 1986). The correlations and results of the statistical tests are contained in Table 2. Premorbid sexual adjustment was moderately related to social skill in schizophrenic and schizoaffective patients, but not in affective disorder patients. Premorbid social adjustment was not related to social skill in any diagnostic group.

\section{Diagnostic, subdiagnostic, and sex differences in social competence}

Descriptive statistics for premorbid adjustment (the sum of standardized premorbid social and sexual adjustment scores) and social skill (the sum of OSS, NS, and VS) for males and females across the three diagnostic groups are presented in Table 3.

Table 3. Descriptive Statistics of Standardized Premorbid Adjustment and Social Skill Scores for Male and Female Schizophrenics, Schizoaffectives, and Affective Disorder Patients

\begin{tabular}{lcccccccc}
\hline & \multicolumn{3}{c}{ Premorbid adjustment } & \multicolumn{3}{c}{ Social skill } \\
\hline \multicolumn{4}{c}{ Male } & \multicolumn{3}{c}{ Female } & \multicolumn{3}{c}{ Male } & \multicolumn{1}{c}{ Female } \\
Diagnosis & Mean & SD & Mean & SD & Mean & SD & Mean & SD \\
Schizophrenia & -.68 & 1.74 & -.26 & 1.76 & -2.24 & 2.50 & -.18 & 2.13 \\
Schizoaffective & -.02 & 1.65 & .78 & .79 & -.33 & 2.27 & .82 & 1.82 \\
Affective & .48 & 1.78 & 1.25 & 1.36 & .72 & 1.60 & .36 & 1.63 \\
\hline
\end{tabular}

Note: high means denote better premorbid adjustment and social skill. 
Diagnostic and sex differences in social competence were examined by performing a multivariate analysis of variance (MANOVA), with premorbid adjustment and social skill as the dependent variables, and diagnosis, sex, and their interaction as the independent variables. The multivariate $F$ 's were significant for diagnosis $[F(4,178)=5.11, P<.001]$, $\operatorname{sex}\{F(2,88)=3.44, P<.04\}$, and the sex-diagnosis interaction $|F(4,178)=2.42, P<.05|$. Univariate ANOVAs were significant for social skill and diagnosis $\mid F(2,89)=7.12, P<.001]$, $\operatorname{sex} \mid F(1,89)=3.93, P<.05]$, and the interaction $[F(2,89)=3.82, P<.03]$. Females were more socially skilled than males. A Duncan's Multiple Range Test indicated that schizophrenics were less skilled than either the schizoaffective or affective patients, who did not differ. The sex by diagnosis interaction was due to the fact that male affective patients had higher social skill than female affective patients, but male schizophrenics and schizoaffectives were less skilled than their female counterparts.

For premorbid adjustment, ANOVAs were significant for diagnosis $\mid F(2,89)=6.65$, $P<.002]$ and $\operatorname{sex}[F(1,89)=4.41, P<.04]$, but not the interaction $[F(2,89)=0.49$, n.s. $]$. Females had better premorbid adjustment than males. A Duncan's Multiple Range Test indicated that the premorbid adjustment of schizophrenics was significantly worse than affectives, with schizoaffectives in between and not different from either group.

Paranoid schizophrenics have been found to have better premorbid functioning than nonparanoids in some previous research (e.g., GoLDSTEIN, 1978), but not all research (e.g., Johnson, Magara, \& STERn, 1986). To determine whether paranoid schizophrenics differed from undifferentiated schizophrenics in premorbid adjustment or social skill, a MANOVA was performed with paranoid-undifferentiated subtype as the independent variable and premorbid adjustment and social skill as the dependent variables. The results of this analysis were not statistically significant $[F(2,48)=0.57$, n.s. $]$, suggesting that paranoid schizophrenics did not have better premorbid adjustment or social skill than undifferentiated schizophrenics.

\section{Chronicity and social competence}

The relations between social competence and chronicity of illness were examined by computing Pearson correlations separately for each diagnostic group between each of the social competence measures (premorbid adjustment and social skill) and the following variables: age, age of onset (first contact with mental health professional), duration of illness, total previous months spent hospitalized, and number of prior hospitalizations. The correlations are presented in Table 4, as are the results of Fisher's $r$ to $z$ transformation to test the difference between the correlations. Patients with poor premorbid adjustment tended to have an earlier age of onset of the illness, and for the schizophrenic and affective patients had been hospitalized more than good premorbid patients. Among schizophrenics, older patients, patients with longer duration of illness, and patients who had spent more time in the hospital were more socially skilled than younger patients with a more recent onset of their illness. However, these correlations were not statistically significantly stronger than for the affective and schizoaffective patients, when tested using Fisher's $r$ to $z$ transformation.

\section{Neuroleptic medications}

Neuroleptic medications can cause extrapyramidal side effects such as akinesia and 
Table 4. Correlations of Age and Chronicity Variables with Social Competence (Premorbid Adjustment and Social. Skill) for Schizophrenics (S), Schizoaffectives (SA), and Affective Disorder (A) Patients

\begin{tabular}{lllllll}
\hline & \multicolumn{2}{c}{ Premorbid adjustment } & \multicolumn{3}{c}{ Social skill } \\
\hline Age & $\mathrm{S}$ & $\mathrm{SA}$ & $\mathrm{A}$ & $\mathrm{S}$ & $\mathrm{SA}$ & $\mathrm{A}$ \\
Age of onset & .12 & $.50^{*}$ & $.46^{*}$ & $.25^{*}$ & .22 & .09 \\
Duration of illness (years) & $.41 \ddagger$ & $.65 \dagger$ & $.39^{*}$ & -.06 & .18 & .13 \\
Prior months in hospital & -.12 & .27 & .18 & $.29^{*}$ & .18 & -.07 \\
Prior hospitalizations & $-.21^{*} \S$ & $.31 \S \mid$ & $-.34^{*} \|$ & $.25^{*}$ & .15 & -.05 \\
\end{tabular}

Note: ${ }^{*}=p<.05 ; \dagger=p<.01 ; \ddagger=p<.001$; High scores on premorbid adjustment and socal skill denote superior competence.

$\S$ Significantly different correlations, Fisher's $r$ to $Z$ transformation $[Z=2.22, P<.04$ (two-tailed) $]$.

II Significantly different correlations, Fisher's $r$ to $Z$ transformation $[Z=2.22, P<.04$ (two-tailed)].

pseudoparkinsonism, which can resemble negative symptoms and social skill deficits. To evaluate whether patients receiving neuroleptics in the three diagnostic groups differed in the dosages of medication prescribed, a one-way ANOVA was performed with chlorpromazine equivalent (DAVIs, 1976) as the dependent variable; this analysis was highly significant $[F(2,87)=8.03, P<.0007]$. A Duncan's Multiple Range Test indicated that schizoaffectives $(N=14$, mean $=1428.5)$ received higher doses of neuroleptics than either affective disorder patients $(N=21$, mean $=690.4)$ or schizophrenics $(N=55$, mean $=882.5)$, who did not differ. Within the schizophrenic group, Pearson correlations were computed between chlorpromazine equivalent dose, social skill, and negative symptoms. None of these correlations approached significance $\left(P_{\mathrm{S}}>.10\right)$.

\section{Social competence and clinical measures}

MANOVAs were conducted comparing male and female schizophrenics on the clinical variables (BPRS, SANS, SAS, QLS). Nonc of thesc analyses was significant $\left(P_{\mathrm{S}}>.10\right)$, and thus sex was excluded from analyses of social competence and clinical measures. To determine whether premorbid adjustment and overall social skill were differentially related to current social adjustment and symptomatology in the schizophrenic sample, hierarchical multiple regressions were performed. These analyses were not performed on the schizoaffective or affective groups due to their small sample sizes. For each regression, the subscale of the clinical measure (e.g., Work Adjustment subscale on the SAS) was the dependent variable, and the premorbid adjustment and social skill measures were the two independent variables. Since premorbid adjustment reflects social competence prior to the illness, and an adequate repertoire of social skills is hypothesized to be necessary for current social competence, premorbid adjustment was forced into the regression equation first and the variance in the dependent variable it explained $\left(R^{2}\right)$ was examined. Then, social skill was entered in the model and the increment in variance explained by adding social skill to premorbid adjustment was examined. Finally, the overall significance of premorbid adjustment and social skill combined in predicting the dependent variable was evaluated. This analysis permitted an independent evaluation of the contributions of premorbid adjustment and social skill to current domains of functioning of the schizophrenic patients (i.e., psychopathology, social adjustment). 
Table 5. Summary of Hierarchical Multiple Regressions for Schizophrenics Predicting Social Adjustment and Symptomatology Following an Exacerbation (rows) from Premorbid Adjustment and Social Skill (COLUMNS)

\begin{tabular}{|c|c|c|c|c|c|c|c|}
\hline \multicolumn{8}{|c|}{ Independent variables } \\
\hline & \multicolumn{2}{|c|}{ Premorbid adjustment } & \multicolumn{2}{|c|}{ Social skill } & \multicolumn{3}{|c|}{ Overall model } \\
\hline & Beta & $\mathrm{R}^{2}$ Change & Beta & $\mathrm{R}^{2}$ Change & $\mathrm{d} f$ & F & Multiple $\mathrm{R}^{2}$ \\
\hline \multicolumn{8}{|l|}{$\begin{array}{l}\text { Dependent variables } \\
\text { Clinical subscale }\end{array}$} \\
\hline \multicolumn{8}{|l|}{ SAS } \\
\hline Work & .05 & .02 & $.53 \S$ & .27 & 2,36 & $7.27 \ddagger$ & .29 \\
\hline Household & .01 & .01 & $.38^{*}$ & .13 & 2,40 & $3.38^{*}$ & .14 \\
\hline External family & .04 & .01 & .13 & .01 & 2,41 & 0.54 & .02 \\
\hline Social/leisure & .06 & .02 & .25 & .06 & 2,50 & 2.14 & .08 \\
\hline General adjustment & -.12 & .01 & $.36^{*}$ & .12 & 2,50 & $3.45^{*}$ & .13 \\
\hline \multicolumn{8}{|l|}{ QLS } \\
\hline Interpersonal relations & .13 & .04 & .24 & .06 & 2,49 & 2.59 & .10 \\
\hline Instrumental role & $.26^{*}$ & .12 & $.34 *$ & .10 & 2,49 & $6.93 \ddagger$ & .22 \\
\hline Intrapsychic foundations & .05 & .03 & $.50 \S$ & .23 & 2,49 & $8.84 \S$ & .26 \\
\hline Common activities & .06 & .02 & .24 & .05 & 2,49 & 1.83 & .07 \\
\hline \multicolumn{8}{|l|}{ SANS } \\
\hline Blunting & .03 & .01 & $-.45 \ddagger$ & .19 & 2,49 & $6.09 \ddagger$ & .20 \\
\hline Alogia & .08 & .00 & $-.36^{*}$ & .12 & 2,49 & $3.43^{*}$ & .12 \\
\hline Apathy & -.14 & .05 & -.27 & .06 & 2,49 & $3.20^{*}$ & .11 \\
\hline Asociality & $-.19^{*}$ & .08 & $-.28^{*}$ & .07 & 2,49 & $4.14^{*}$ & .15 \\
\hline Attention & -.13 & .04 & --.26 & .06 & 2,49 & 2.71 & .10 \\
\hline
\end{tabular}

Note: Positive Beta weights reflect social competence (premorbid adjustment and social skill) is associated with better social adjustment and worse symptoms.

${ }^{*}=P<.05 ; \mid P<.01 ; \ddagger=P<.005 ; \S=P<.001$.

For the schizophrenic group, significant effects were obtained for most of the subscales on the QLS, SAS, and the SANS. Table 5 summarizes the results of these regressions. Degrees of freedom in the analyses vary due to missing data. For all the significant effects, patients with higher social competence were more socially adjusted and had fewer negative symptoms. Premorbid adjustment was significantly related to two subscales, Asociality (SANS) and Instrumental Role Functioning (QLS). Social skill was related to eight subscales, some at highly significant levels. No subscales on the BPRS were related to premorbid social adjustment or social skill $(P>.10)$, despite an acceptable range and distribution of scores for each scale. It is noteworthy that the anergia subscale on the BPRS was not related to either premorbid adjustment or social skill, even though other investigators have reported that it is correlated with other measures of negative symptoms (CARPENTER, HEINRICHS, \& Wagman, 1988).

To examine the pathway from premorbid adjustment to current social skill to current psychopathology and social adjustment in schizophrenia correlations and partial correlations were computed between these measures. For this analysis, Overall Social Skill was used as the measure of social skill, the sum of the BPRS and SANS subscales was the index of psychopathology, and the sum of the SAS and QLS subscales was the index of social adjustment. The influence of gender and age were not included in this analysis, since neither was found to be significantly correlated with either psychopathology or social adjustment. 


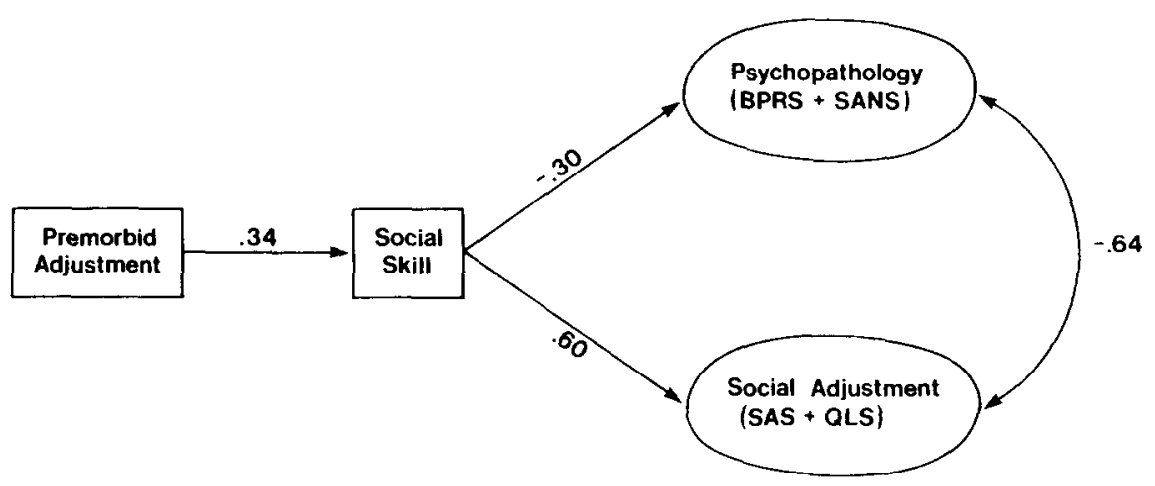

FIG. 1. Path diagram illustrating the relationships between premorbid adjustment and social skill with psychopathology and social adjustment. Zero-order correlations are presented for premorbid adjustment and social skill, and for psychopathology and social adjustment. Partial correlations are presented for social skill and psychopathology, and for social skill and social adjustment, controlling for the correlation between premorbid adjustment and these variables. All correlations are significant at or beyond $P<.05$.

Zero-order correlations were computed between premorbid adjustment and social skill, and between psychopathology and social adjustment. Partial correlations were computed between social skill and psychopathology and social adjustment, partialing out the effects of premorbid adjustment on these variables. 'l'hese correlations are illustrated in a hypothetical model in a path diagram (Fig. 1). It can be seen from this diagram that premorbid adjustment is moderately correlated with social skill, which in turn is correlated strongly with social adjustment and moderately with psychopathology.

\section{DISCUSSION}

Moderately significant correlations were found for the schizophrenic and schizoaffective patients between premorbid sexual adjustment and measures of social skill. Since premorbid adjustment is assumed to be a general indicator of social competence before the onset of the illness (ZIGLER \& GLICK, 1986), whereas social skills (assessed after the illness) are believed to be necessary to achieve social competence (LIBERMAN et al., 1986b), relations between these constructs suggest that poor social skill may antedate the onset of schizophenia. The correlations between social skill and premorbid adjustment do not permit an inference as to the functional relationship of social skill to premorbid adjustment. Nevertheless, the data suggest some stability to social competence over the course of schizophrenia, and raise the question of whether skill deficits are present even earlier, such as during childhood.

Lewine, WATt, Prenbey, and Fryer (1980) found that schizophrenic patients had lower premorbid childhood social competence, but not academic competence, than other patients, when competence was measured retrospectively based upon ad lib teachers comments recorded in school records. However, childhood social competence was not significantly correlated with adult premorbid adjustment (LEWINE, WATT, \& FRYER, 1978), although the correlation was in the expected direction $(r=.20, n . s$. $)$. The relationship of social skill 
to poor childhood and adult premorbid social competence needs to be addressed in prospective research, such as in a high risk population. This approach would also shed light on whether focal skill deficits or poor social competence before the illness are an early manifestation of schizophrenia (i.e., a disease marker) or represent a behavioral risk factor that increases the likelihood of developing the illness in biologically vulnerable persons (Pogue-Geile \& Zubin, 1988).

Schizophrenic patients had the lowest premorbid adjustment and social skill, followed by schizoaffectives, and then affective disorder patients. These results are in line with longitudinal studies showing that the social adjustment and outcome of schizoaffective patients falls between that of schizophrenic and affective patients (HARRow \& Grossman, 1984; ANGST, 1986). The superior premorbid functioning and social skill of female schizophrenic and schizoaffective patients is consistent with other research on sex differences in social competence in this population (LEWINE, 1981; ZigleR \& GLICK, 1986).

In the affective group, females had better premorbid adjustment than males, but did not have better social skills. Furthermore, among affective patients neither premorbid social nor sexual adjustment was related to any measures of social skill. Previous research has suggested that premorbid functioning is unrelated to outcome for nonschizophrenic patients (Rosen et al., 1969; Bromet, Harrow, \& Kasl, 1974; Westermeyer \& Harrow, 1986), although some studies have reported such a relationship (ZIGLER, GliCK, \& MARSH, 1979). The lack of correlation between premorbid adjustment and social skill for affective patients suggests that social competence may be less stable over the course of affective disorders than schizophrenic-spectrum disorders. Alternatively, premorbid adjustment and social skill may reflect different dimensions of social competence in the two disorders. Of course, it is also possible that the sinall sample of affective patients yielded unreliable data. However, the pattern of correlations between premorbid adjustment and social skill in the smaller group of schizoaffective patients was quite similar to the schizophrenic patients. These analyses should be replicated with a larger sample.

Poor premorbid adjustment was related to two current domains of functioning in the schizophrenic patients that might be among the most logical measures to reflect gross social impairment: high Asociality (SANS) and worse Instrumental Role Functioning (QLS). In contrast, social skill (which was entered second in the hierarchical multiple regression after premorbid adjustment) was consistently related to most of the social adjustment subscales and to negative (deficit) symptoms as well, but not to positive symptoms. More socially skilled schizophrenic patients tended to have better social adjustment and fewer negative symptoms. Naturally, since premorbid adjustment refers to social competence before the illness, current social skill would be expected to be more strongly related to morbid functioning than premorbid adjustment.

With respect to social adjustment, social skill was more related to performance on instrumental tasks (e.g., work adjustment, household responsibilities) than the quality of interpersonal relationships and leisure time. This finding is intriguing, since the role plays assessed social skill in interpersonal situations (e.g., initiating a conversation with another person), rather than instrumental situations (e.g., responding to a criticism from an employer). These role play interactions were relatively brief, consisting of only three verbal exchanges between the patient and the confederate. Thus, they probably did not tap social 
skills critical for maintaining interpersonal relationships, as opposed to initiating relationships (e.g., ClarK, ChrisrofF, \& HANSEN, 1986). Assessments of social skill based on extended social interactions might identify skills more relevant to other aspects of interpersonal relationships.

Premorbid adjustment was correlated with age of onset for all three diagnostic groups, and was related to cumulative time spent in the hospital for the affective and schizophrenic patients. Thus, premorbid adjustment appears to reflect vulnerability to an earlier age of onset of illness and subsequent relapses, without predicting the severity of symptoms or social maladjustment. An intriguing finding was that older schizophrenics with a longer duration of illness who had spent more time hospitalized were more socially skilled than younger, less chronic patients. While this result appears to be inconsistent with the presumed deleterious effects of institutionalization (e.g., WING \& BROWN, 1970), it may reflect the diminution of symptoms and social impairment later in the lives of schizophrenics (BLEULER, 1978; CIOMPI, 1980; BRIDGE et al., 1978). The higher social skill of more chronic patients could also be due to differences in severity of illness requiring hospitalization (i.e., chronic patients hospitalized when less severely ill) or a greater tendency for older ill patients to be in state hospitals than younger ones.

A methodological limitation of the current study was that assessments of social skill, symptoms, and social adjustment were conducted within several weeks following a hospitalization, and that these assessments may reflect the recent exacerbation of symptoms. This study raises two important questions about the relations between premorbid and morbid social competence and the outcome of schizophrenia that can only be answered with prospective, longitudinal research: (1) do social skill deficits antedate the onset of schizophrenia, and if so how are they related to the development of the illness?; and (2) do social skills, and hence social competence impact on the course of schizophrenia or are they simply a reflection of the severity of the illness and its probable outcome? Longitudinal data with multiple assessments over time using the same instruments would permit a path analysis to be conducted that would disentangle the influence of social competence on the course of schizophrenia. The partial correlational analysis, illustrated in the path diagram (Fig. 1), suggests that social competence may influence social adjustment, and to a lesser extent psychopathology. Finally, the data also suggest that the premorbid adjustment and morbid social skill of schizophrenics and schizoaffectives both reflect social competence and some temporal stability over the course of the illness.

Acknowledgements-This research was supported by NIMH grants MH 38636 and MH 39998 , and by a grant to the first author from the National Alliance for Research in Schizophrenia and Depression (NARSAD). Appreciation is extended to Paul R. Yarnold and Steve Sayers for statistical consultation and to Lori Bond, Leonard Burns, Margaret Douglas, Pam Fawcett, Tamara Murdock, Colleen Quinn, Susan Rappaport, Eileen Wade, and Julie Wade for their help on the project.

\section{REFERENCES}

American Psychiatric Association (1987). Diagnostic and statistical manual of mental disorders (3rd ed.). Washington, D.C.: Author.

Andreasen, N. C. (1982). Negative symptoms in schizophrenia. Archives of General Psychiatry. 39, 784-788. ANGST, J. (1986). The course of schizoaffective disorders. In A. Maneros \& M. T. Tsuang (Eds.), Schizoaffective psychosis (pp. 63-93). New York: Springer. 
ARGYLE, M. F, (1981). The contribution of social interaction research to social skills training. In J. D. Wine \& M. D. Srnye (Eds.), Social Competence, (pp. 261-286). New York: Guilford.

BELlACK, A. S. (1983), Recurrent problems in the behavioral assessment of social skills. Behaviour Research and Therapy. 21, 29-42.

Bellack, A. S. Turner, S. M., Hersen, M., \& Luber, R. F. (1984). An examination of the efficacy of social skills training for chronic schizophrenic patients. Hospital and Community Psychiatry. 35, 1023-1028.

Bleuler, M. (1978). The schizophrenic disorders: long-term patient and family studies. New Haven: Yale University Press.

Boswell, P. C., \& Murray, E. J. (1981). Depression, schizophrenia, and social attraction. Journal of Consulting and Clinical Psychology. 49, 641-647.

Bridge, T. P., Cannon, H. E., \& Wyatt, R. J. (1978). Burned-out schizophrenia: evidence for age effects on schizophrenic symptomatology. Journat of Gerontology. 33, 835-839.

Bromet, E., Harrow, M., \& Kasl, S. (1974). Premorbid functioning and outcome in schizophrenics and nonschizophrenics. Archives of General Psychiatry. 30, 203-207.

Carpenter, W. T., Heinrichs, D. W., \& Wagman, A. M. T. (1988). Deficit and nondeficit forms of schizophrenia: The concept. American Journal of Psychiatry. 145, 578-583.

Ciompi, L. (1980). The natural history of schizophrenia in the long term. British Journal of Psychiatry. 136, 413-420.

Clark, K. A. Christoff, K. A., \& Hansen, D. J. (1986). Friendship-making training for psychiatric aftercare clients. Journal of Partial Hospitalization. 3, 273-284.

Davis, J. M. (1976). Comparative doses and costs of antipsychotic medications. Archives General Psychiatry. 33, $858-861$.

DeJong, A., Giel, R., Slooff, C. J., \& Wiersma, D. (1985). Social disability and outcome in schizophrenic patients. British Journal of Psychiatry. 147, 631-636.

ENDICOTT, J. \& SPITZER, R. L. (1978). A diagnostic interview: the schedule for affective disorders and schizophrenia. Archives of General Psychiatry. 35, 837-844.

Goldstein, M. J. (1978). Further data concerning the relation between premorbid adjustment and paranoid symptomatology. Schizophrenia Bulletin. 4, 236-243.

Harris, J. G., Jr. (1975). An abbreviated form of the Phillips Rating Scale of Premorbid Adjustment in Schizophrenics. Journal of Abnormal Psychology. 84, 129-137.

Harrow, M., \& Grossman, L. S. (1984). Outcome in schizoaffective disorders: A critical review and reevaluation of the literature. Schizophrenia Bulletin. 10, 87-108.

Heinrichs, D. W., Hanlon, T. E., \& Carpenter, W. T. (1984). The Quality of Life Scale: An instrument for rating the schizophrenic deficit syndrome. Schizophrenia Bulletin. 10, 388-398.

Hogarty, G. E., Anderson, C. M., Reiss, P. J., Kornblith, S. J., Greenwald, D. P., Javna, C. D., \& Madonia, M. J. (1986). Family psycho-education, social skills training and maintenance chemotherapy in the aftercare treatment of schizophrenia: 1 . One year effects of a controlled study on relapse and expressed emotion. Archives of General Psychiatry. 43, 633-642.

Iollingshead, A. B., \& Redlich, F. C. (1958). Social class and mental illness: A community study. New York: Wiley.

Johnson, M. H., Magaro, P. A., \& Stern, S. L. (1986). Use of the SADS-C as a diagnostic and symptom severity measure. Journal of Consulting and Clinical Psychology. 54, 546-551.

Kay, S. R., \& Lindenmayer, J. (I987). Outcome predictors in acute schizophrenia: Positive significance of background and clinical dimensions. Journal of Nervous and Mental Disease. 175, 152-160.

LEWINE, R. R. J. (1981). Sex differences in schizophrenia: Timing of subtypes? Psychological Bulletin. 90, 432-444.

LEWINE, R. R. J., WATT, N. F., \& FRYER, J. H. (1978). A study of childhood social competence, adult premorbid competence, and psychiatric outcome in three schizophrenic subtypes. Journal of Abnormal Psychology. 87, 294-302.

Lewine, R. R. J., Watt, N. F., Prentky, R. A., \& Fryer, J. H. (1980). Childhood social competence in functionally disordered psychiatric patients and controls. Journal of Abnormal Psychology. 89, $132-138$.

Liberman, R. P., Mueser, K. T., \& Wallace, C. J. (1986a). Social skills training for schizophrenic individuals at risk for relapsc. American Journal of Psychiatry. 143, 523-526.

Liberman, R. P., Mueser, K. T., Wallace, C. J., Jacobs, T. E., Eckman, T. \& Massel, H. K. (1986b). Training skills in the psychiatrically disabled: Learning coping and competence. Schizophrenia Bulletin. 12, 631-647.

Overall, J. E., \& Gorham, D. R. (1962). The Brief Psychiatric Rating Scale. Psychological Reports. 18, $799-812$.

Phillips, L. (1953). Case history data and prognosis in schizophrenia. Journal of Nervous and Mental Disease. $117,515-525$.

Pogue-Geile, M. F., \& Zubin, J. (1988). Negative symptomatology and schizophrenia: A conceptual and empirical review. International Journal of Mental Health. 16, 3-45. 
Rosen, B., Klein, D. F., Levenstein, S., \& Shahinian, S. P. (1969). Social competence and post hospital outcome among schizophrenic and nonschizophrenic psychiatric patients. Journal of Abnormal Psychology. 74, 401-404. Schooler, N., HogartY, G., \& Weissman, M. (1978). Social Adjustment Scale II (SAS-II). In W. A. Hargreaves, C. C. Atkisson, \& J. E. Sorenson (Eds.), Resource Materials for community mental health program evaluations. Rockville, MD: DHEW.

SERBAN, G. (1975). Functioning in schizophrenia and "normal" subjects. Short-term prediction for rehospitalization of schizophrenics. Comprehensive Psychiatry. 16, 447-456.

SPITZER, R. L., \& WIILIAMS, J. B. W. (1985). Structured Clinical interview for DSM-III-psychotic disorders version. New York: New York State Psychiatric Institute.

Strauss, J. S., \& Carpenter, W. T. (1977). Prediction of outcome in schizophrenia. Archives of General Psychiatry. 34, 159-163.

Strauss, J. S., Klorman, R., Kokes, R. F., Sacksteder, J. (1977). Premorbid adjustment in schizophrenia: Concepts, measures, and implications. Part V. The implications of findings for understanding research and application. Schizophrenia Bulletin. 3, 240-244.

Westermeyer, J. F., \& Harrow, M. (1986). Predicting outcome in schizophrenics and nonschizophrenics of both sexes: The Zigler-Phillips Social Competence Scale. Journal of Abnormal Psychology. 95, 406-409.

WING, J. K., \& BRown, G. W. (1970). Institutionalization and schizophrenia. London: Cambridge University Press. ZIGLER, E., \& GLICK, M. (1986). A developmental approach to adult psychopathology. New York: Wiley.

Zigler, E., Glick, M., \& Marsh, A. (1979). Premorbid social competence and outcome among schizophrenic and nonschizophrenic patients. Journal of Nervous and Mental Disease. 167, 478-483.

Zigler, E., \& Phillips, L. (1961). Social competence and outcome in psychiatric disorder. Journal of Abnormal and Social Psychology. 63, 264-271.

Zubin, J., \& Spring, B. (1977). Vulnerability-A new view of schizophrenia. Journal of Abnormal Psychology. 86, 103-126. 